\title{
INVESTIGATION OF FORCES ACTING ON PLAIN DISCS
}

\author{
S. M. Mpanduji ${ }^{\S}$, Makungu P.J and Lazaro E.L \\ Department of Agricultural Engineering, SUA, P.O. Box 3003, Morogoro, Tanzania
}

$T$

his paper presents the results of the investigation of mutually perpendicular forces generated by rotating and non-rotating plain discs, which are similar to those, used to counteract the high side forces generated by disc ploughs. The experiments were carried out in a soil bin containing sand loam soil (Ryton sand). The forces were measured whilst changing the disc rake and sweep angles.

Results showed that all mutually perpendicular forces generated by the discs changed significantly with change in the disc sweep and rake angles. The draught forces generated by a non-rotating disc were higher than those generated by a rotating disc, however the vertical and the lateral forces encountered by a nonrotating disc were lower than those generated by a rotating disc. In that case the rotating disc was found to be suitable for counteracting high side forces generated by disc ploughs because of the less draught and higher lateral forces generated by this disc than that of the non-rotating plain disc. The recommended optimum angles lie between $8^{\circ}-12^{\circ}$ for disc sweep angle and $80^{\circ}-95^{\circ}$ for disc rake angle.

Keywords: Angle, Disc, Force, Soil, Tillage

\section{INTRODUCTION}

Tillage is the practise of modifying the state of the soil in order to provide condition favourable to crop growth. The objectives of tillage are to create good conditions for seed germination and to promote plant growth by loosening, mixing, compacting of the soil, burying plant residues, weed control and increasing or maintaining soil fertility. Tillage is accomplished by using different types of implements, such as mouldboard ploughs, chisel, tines, disc ploughs and harrows.

To achieve efficient and qualitative field operations with minimum energy requirements, it is important to use properly designed implements. This can be realised if analyses of forces of the implements are undertaken (Sheruddin et. al, 1992).

In tropical region, agriculture disc ploughs are widely used for both primary and secondary tillage because these regions often have hard, dry soils which are likely to suffer from wind and water erosion. The disc plough has the advantage of good penetration and leaves some crop residues on the soil surfaces, which help the soil to conserve water and to protect it from erosion.

Disc ploughs have a problem of generating high side force due to the lateral moment of the soil (Gill et. al, 1980). To counteract this side force, disc ploughs often have a simple plain disc, spring mounted at the rear of the plough frame. The plain disc is angled to the direction of travel so as to generate lateral force in the opposite direction to the side force developed by the ploughing discs. The lateral force produced by the plough becomes a serious problem in very hard and stony soil conditions. This is because in such conditions the stabilising disc has difficulty in penetrating through the soil surface. The resulting effect is the transfer of lateral force to the linkages of the plough frame. The result is that, the tractor becomes laterally unstable and difficult to steer and sometimes it may results into breakage or damage of the plough frame or linkages of the

$\S$ Author to whom correspondence should be made, Email: smmpanduji@yahoo.com and smmpanduji@suanet.ac.tz 
tractor. In order to avoid these adverse effects it is important to set the plain disc at an optimum angle position. This would be in an attempt to ensure that the disc can generate minimum draught and upward vertical force but at the same time generating maximum lateral force, thus helping to reduce the overall draught of the plough, penetrate well in the soil and to generate maximum stabilising force.

This study was therefore undertaken with the aim of determining forces that act on plain discs when changing the disc sweep and rake angles and then to propose the angles setting (optimum angles) of the plain disc, which results into generating minimum draught force but maximum lateral and downward vertical forces. Literature review has revealed that there is no information published regarding the forces that act on plain discs. However, substantial research has been carried-out on analysis of the forces that act on the concave discs of the disc ploughs, tines and mouldboard ploughs (Clyde, 1939; Gebresenbet, 1989; Godwin et. al, 1987: Payne and Tanner, 1959, Sheruddin et, al, 1992).

The specific objectives were:

1. To investigate the mutually perpendicular forces (draught, vertical and lateral forces) acting on rotating and non-rotating plain discs at different settings of sweep and rake angles.

2. To compare the forces generated by rotating and non-rotating discs.

3. To propose a suitable type of plain disc to be used to counteract the side force generated by disc ploughs and to propose its optimum angle settings.

\section{MATERIAL AND METHODS}

The study was conducted in a soil bin $(6 \mathrm{~m}$ long, $0.83 \mathrm{~m}$ wide and $0.8 \mathrm{~m}$ deep) in laboratory. The soil bin permitted conducting tests under controlled and uniform soil and operating condition. Field test would have reduced the effectiveness of any comparison due to poor soil homogeneity and unpredictable weather as implied by Godwin et al, (1980).

The apparatus, that enabled the variations of sweep and rake angles in the range where the plain disc ploughs are normally set was designed and fabricated. The sweep angle in this context refers to the angle between the plane of the disc and the direction of travel. When the plain disc is set to zero sweep angle, the disc edge rolls along the path of travel. The rake angle refers to the angle between the plane of the disc and the soil surface (Fig.1).

Generally there is no single force acting at a point on a tillage implement working in the soil. On contrary, there are infinite numbers of forces acting on all contact area of the disc, thus forming a system of forces. In mechanics it is possible to simplify the system of forces with the resultant force combination that can replace the original forces without altering the external effect of the forces applied to the contact surface of the disc. In this study therefore, three mutually perpendicular resultant forces were monitored and recorded using three strain gauge transducers. One strain gauge transducer (dynamometer) was placed horizontally to measure the draught force variations and another strain gauge transducer (dynamometer) was placed vertically on the implement carriage frame to measure vertical force variations. The motion of the frame was then restricted only to two directions i.e. vertical and horizontal. The third strain gauge transducer was connected in a form of differential cantilever and was used to measure the variations of the resultant lateral force. The connection enabled measurement of the lateral force irrespective of its position on the disc. 


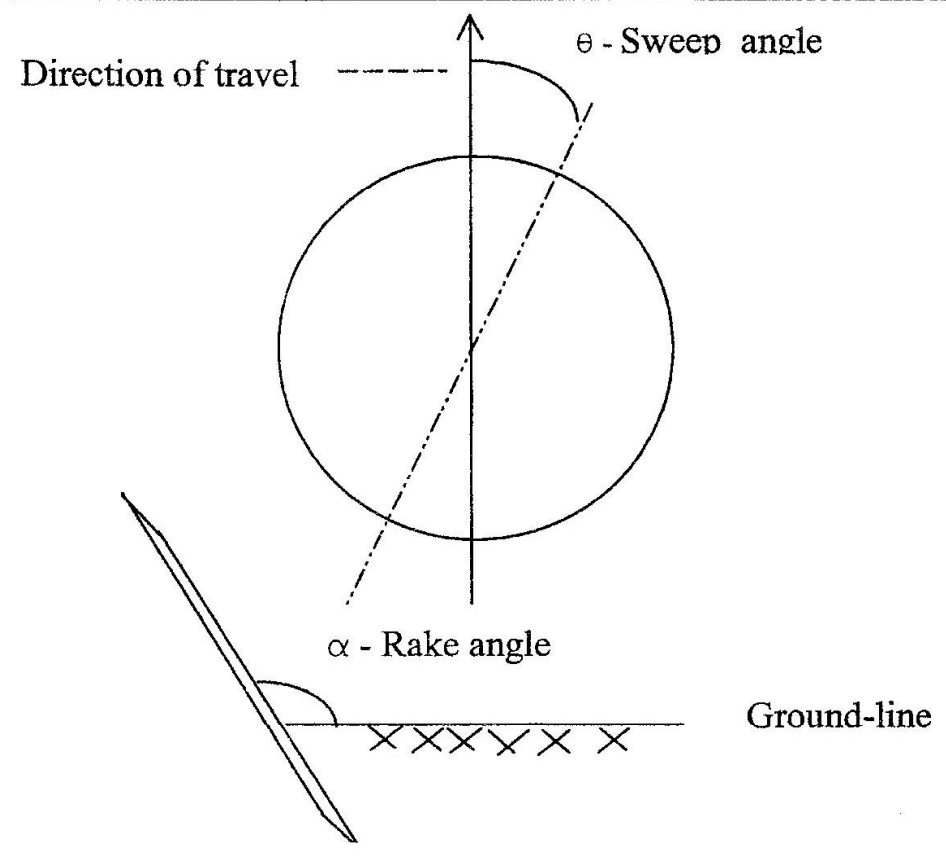

Figure 1. Identification of sweep and rake angle of a plain disc

The instrumentation was calibrated before and at the end of data collection in order to examine the effect of repeated loads on the calibration constants. The calibration process was conducted by applying loads at the point where the resultant forces were considered to act on the frame. The magnitude of the load applied during calibration was estimated using the equation developed by Hettiaratchi and Reece (1974) for tillage blade. The variations in the results obtained before and after data collection were $3 \%, 2 \%$, and $4 \%$ for draught, vertical, and lateral forces respectively. These disparities were considered to be within the acceptable error range (Dally and Riley, 1983).

The output signals in terms of voltage from the three strain gauge transducers were received through three different channels of a datalogger, which sampled data at a rate of 47 readings per second. The signals were then amplified, recorded and displayed on a computer. In the end the computer calculated the mean and standard deviation for each channel. The experimental procedure for every run was performed in such a way that the plain disc was allowed to reach the desired working point before the data-logger was switched on and then switched-off -after the disc had travelled a distance of $3 \mathrm{~m}$ so as to avoid working so close to the end of the soil bin. Sandy loam soil (Ryton sand) with an average moisture content of $6.6 \%$ (wet basis), cohesion of $5 \mathrm{kPa}$, angle of internal friction $35^{\circ}$ and angle of soil-metal friction $22^{\circ}$ was used in the study. Throughout the experiment the soil properties, mainly moisture content and soil bulk density were kept constant in order to increase the repeatability of the results. The soil bulk density was maintained by compacting the soil using the vibrating machine (fixed on the carriage machine in the laboratory) after the disc was run in the soil bin. Always the soil was compacted to an average dry bulk density of about $1550 \mathrm{~kg} / \mathrm{m}^{3}$, similar to the naturally compacted soil found in semi-arid areas in tropics (Macartney et al, 1971).

The $450 \mathrm{~mm}$ diameter plain discs (rotating and non-rotating) were used in the study. During data collection the discs were maintained at a constant working depth of $70 \mathrm{~mm}$. The forward speed of $0.23 \mathrm{~m} / \mathrm{sec}$ was used in running the discs because this was the maximum speed that 
could be attained by the carriage machine in laboratory. In the field normally the adjuster on the disc plough is provided such that the sweep angles of the support disc can be altered but not the rake angles. As a result the sweep angle settings selected ranged from $0^{\circ}$ to $25^{\circ}$ at an interval of $5^{\circ}$, while three different rake angles close to the angle at which the plain disc is normally set were selected, these include $80^{\circ}$, $95^{\circ}$, and $105^{\circ}$. Also for the matter of curiosity, the arbitrary rake angle $60^{\circ}$ was considered. For each disc run, the sweep and rake angles combination were set at random. However, for each setting three repeated runs were performed.

\section{RESULTS AND DISCUSSION}

The variations in draught force with disc sweep angle at different rake angles encountered on a rotating disc (Figure 2) showed that the force variations with sweep angle were similar irrespective of the rake angles settings. The minimum draught force was found to be in the range between $5^{\circ}$ and $15^{\circ}$ sweep angles. However the draught forces were found to increase as the sweep angles were increased above $15^{\circ}$. This effect can be partially explained by the fact that, at larger sweep angles above $15^{\circ}$, larger volumes of soil were being failed ahead of the disc and thus resulting in the increase of draught forces. At $0^{\circ}$ sweep angle the draught force was slightly higher than between $5^{\circ}$ and $15^{\circ}$ sweep angles because at this setting two sides of the disc were in contact with the soil thus generating a large progressively scrubbing reaction. When the sweep angle was increased the contact area decreased because one side of the disc remained in contact with the soil and therefore the scrubbing reaction reduced. The variations of the draught force generated by a non-rotating disc with the change in sweep angles had a trend similar to that observed on a rotating disc (Figure3).

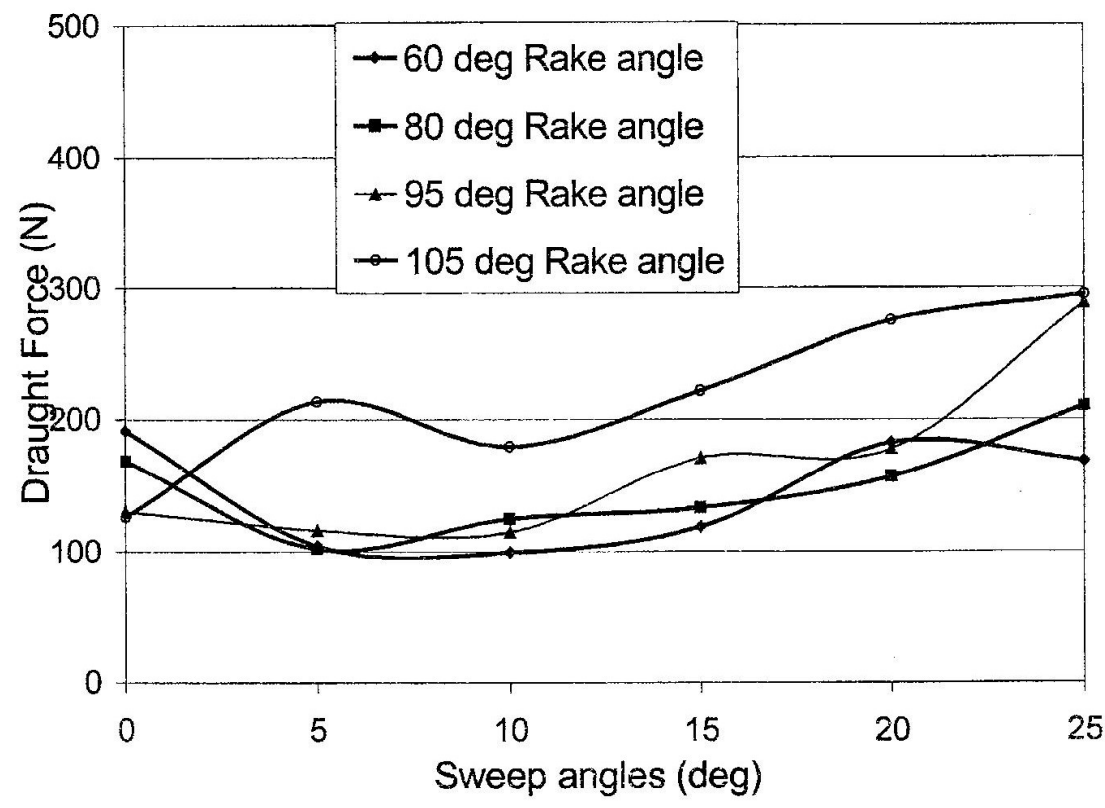

Figure 2. Effect of sweep angle on draught force acting on a rotating disc 


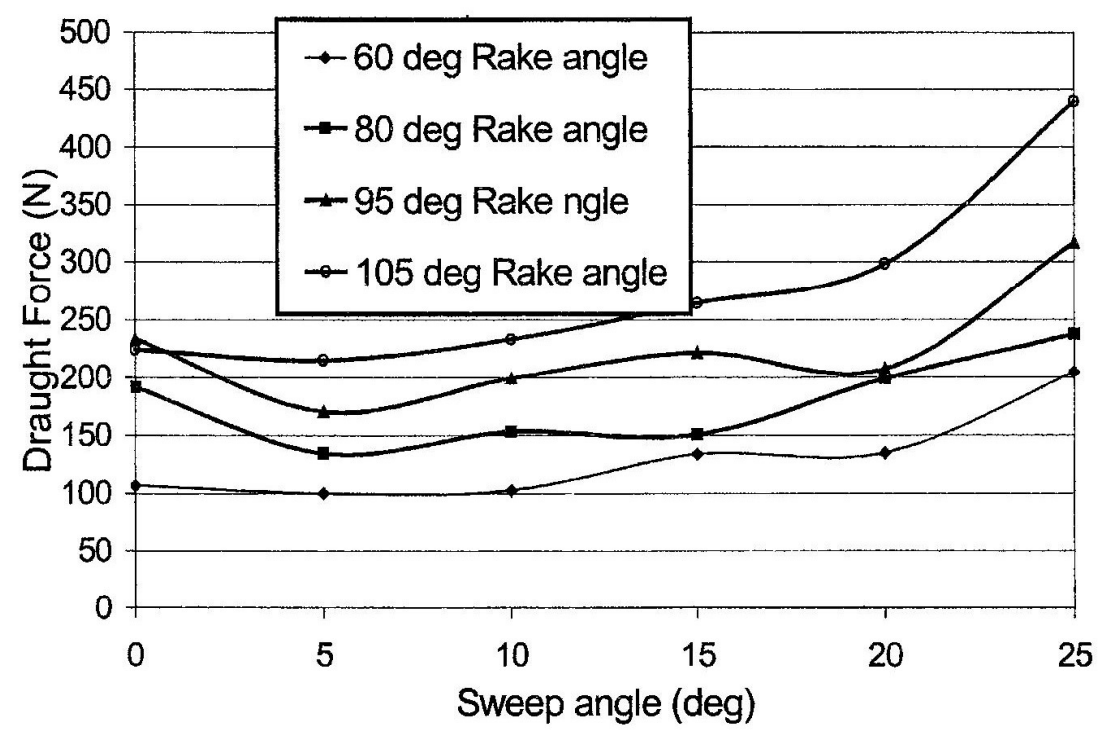

Figure 3. Effect of sweep angle on draught force acting on a non-rotating disc

The variations of the draught force with the change of rake angles for rotating and nonrotating discs showed that there was a fairly uniform increase in draught force as the disc rake angles were increased, irrespective of the settings of disc sweep angles. However the variations of draught force produced by a non- rotating disc were found to be higher than those generated by a rotating disc (Figure 4). This was due to the effect of soil-metal friction. As the soil was flowing over the disc surfaces, the non-rotating disc was experiencing sliding friction, which is greater than the rolling friction experienced by the rotating disc.

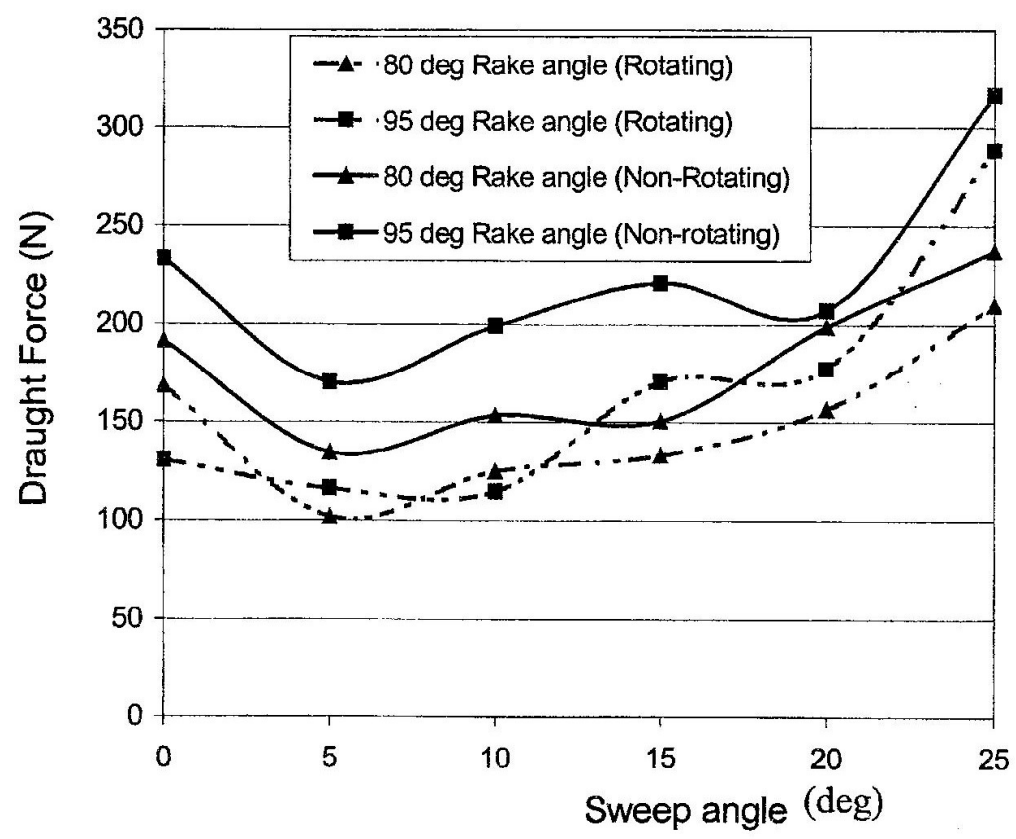

Figure 4. Comparison of the effect of sweep angle on the draught force 
Figure 5 illustrates the effect of sweep and rake angles upon the vertical force generated by a rotating disc. The results showed that the variations of the upward vertical force decreased as the disc sweep angles were increased to around $10^{\circ}$ for rake angles between $60^{\circ}$ and $80^{\circ}$. This might be explained by the fact that at small sweep angles, when the disc rotates, the rolling action of the disc makes it act like a backward raked tine with a disc trying to "roll out" of the soil. As the disc sweep angle was increased to $10^{\circ}$ "the roll out" effect of the cutting edge of the disc decreased and hence the magnitude of the upward vertical force decreased. At sweep angles above $10^{\circ}$ the upward vertical force was found to increase with the increase of disc sweep angles. On the other hand the variations of the upward vertical force increased as the rake angles were increased.

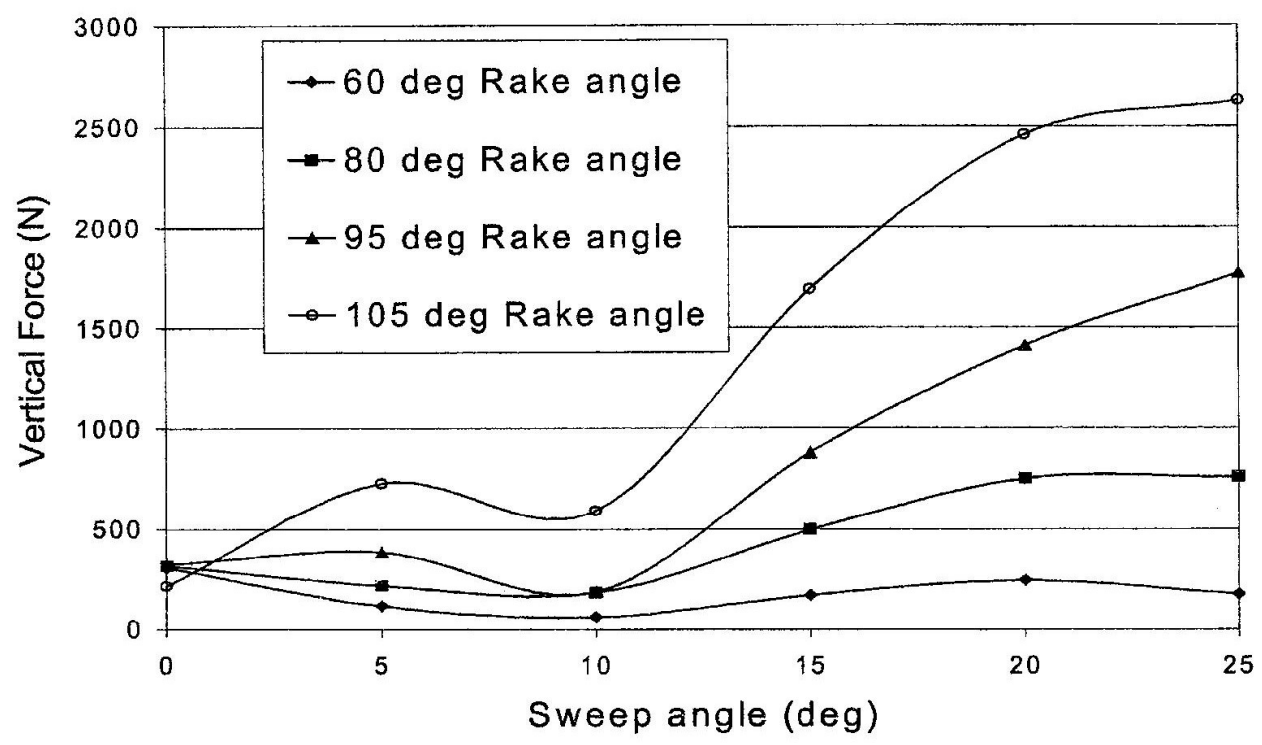

Figure 5. Effect of sweep angle on vertical force acting on a rotating disc

The change in vertical force with sweep and rake angles for a non-rotating disc is shown in Figure 6. Two trends can be clearly observed from this figure to include the trends of vertical force for the disc rake angle below and above $80^{\circ}$. The upward vertical force for the rake angles below $80^{\circ}$ decreased with the increase in disc sweep angles, whereas for the rake angle above $80^{\circ}$ the upward vertical force was found to be almost uniform with the increase of the disc sweep angles.

The variations of upward vertical force generated by a rotating disc were higher than those generated by a non-rotating disc (Figure 7). This could also be partially explained by the effect of "rolling out " experienced by the rotating disc but not on the non-rotating disc.

Figure 8 and 9 show that the variations of the lateral force increased with the increase in the disc sweep angles. A sharp increase of lateral force occurred in the range between $0^{\circ}$ and $8^{\circ}$ sweep angles for both rotating and non-rotating discs. In this range the average increase of the force was found to be about $200 \%$ for every increase in $5^{\circ}$ sweep angle. Above $8^{\circ}$ sweep angle the lateral force was observed to increase at a fairy constant trend, where the increase is about $10 \%$ for the increase of $5^{\circ}$ sweep angle. 


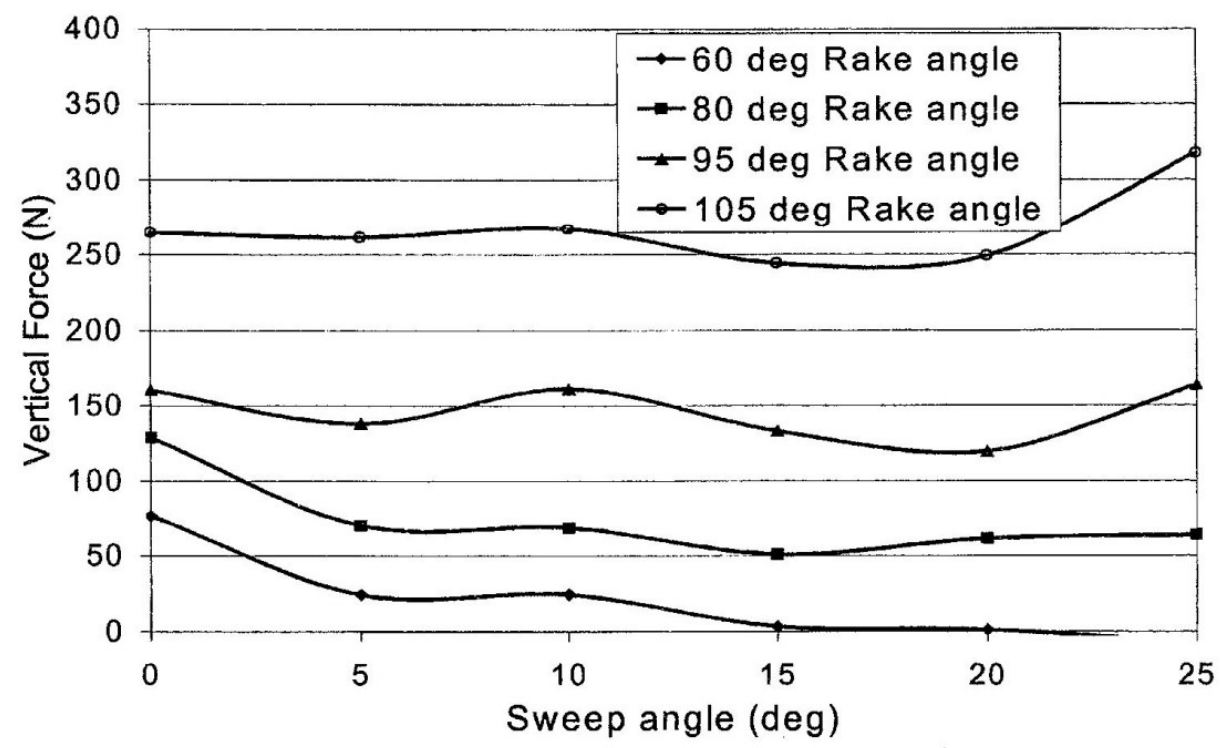

Figure 6. Effect of sweep angle on vertical force acting on a non-rotating disc

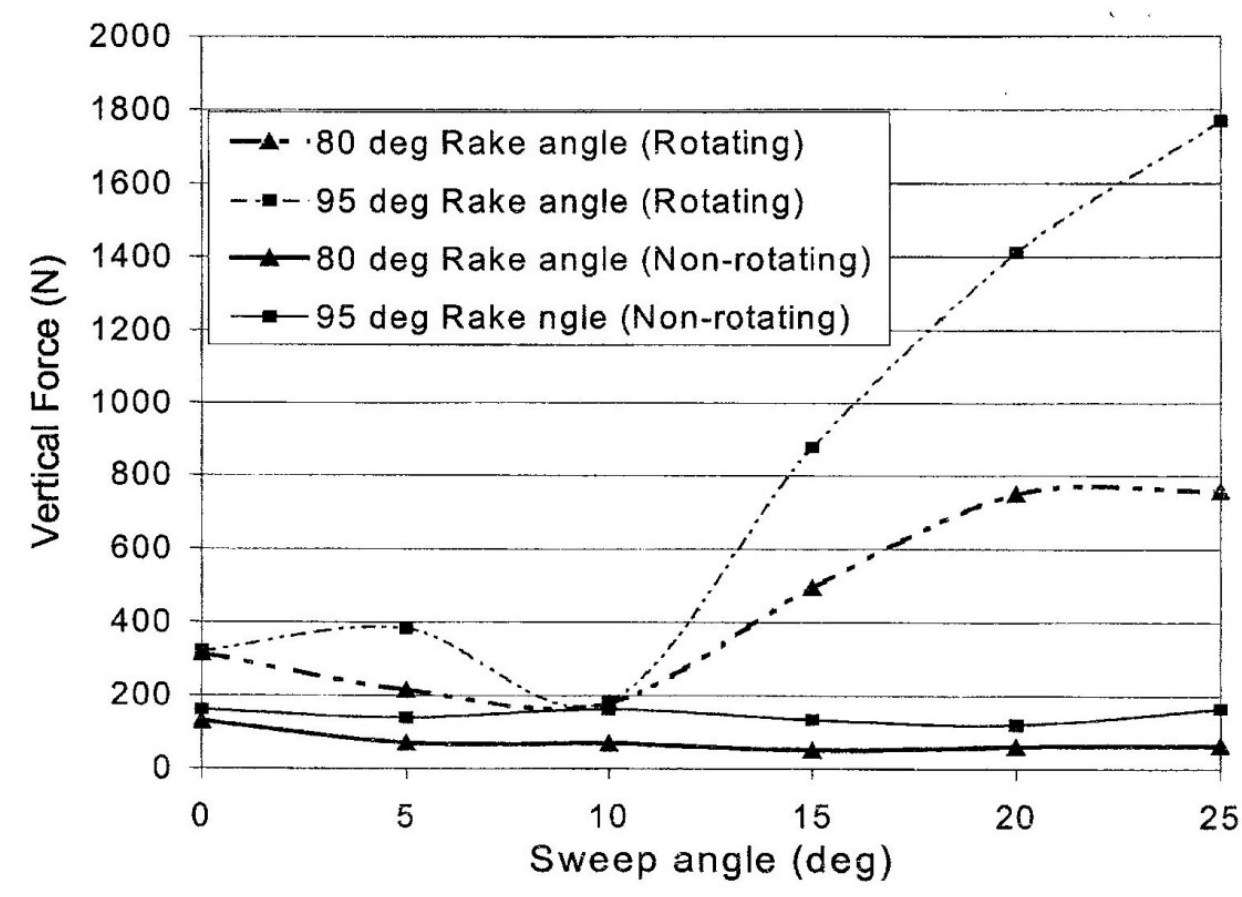

Figure 7. Comparison of the effect of sweep angle on vertical force 


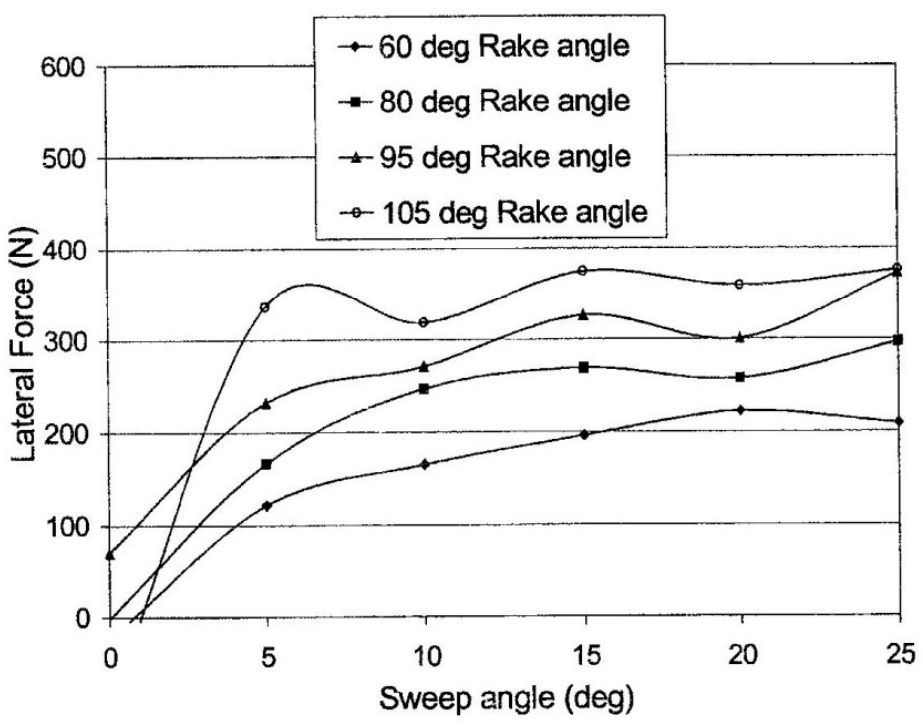

Figure 8. Effect of sweep angle on lateral force acting on rotating disc

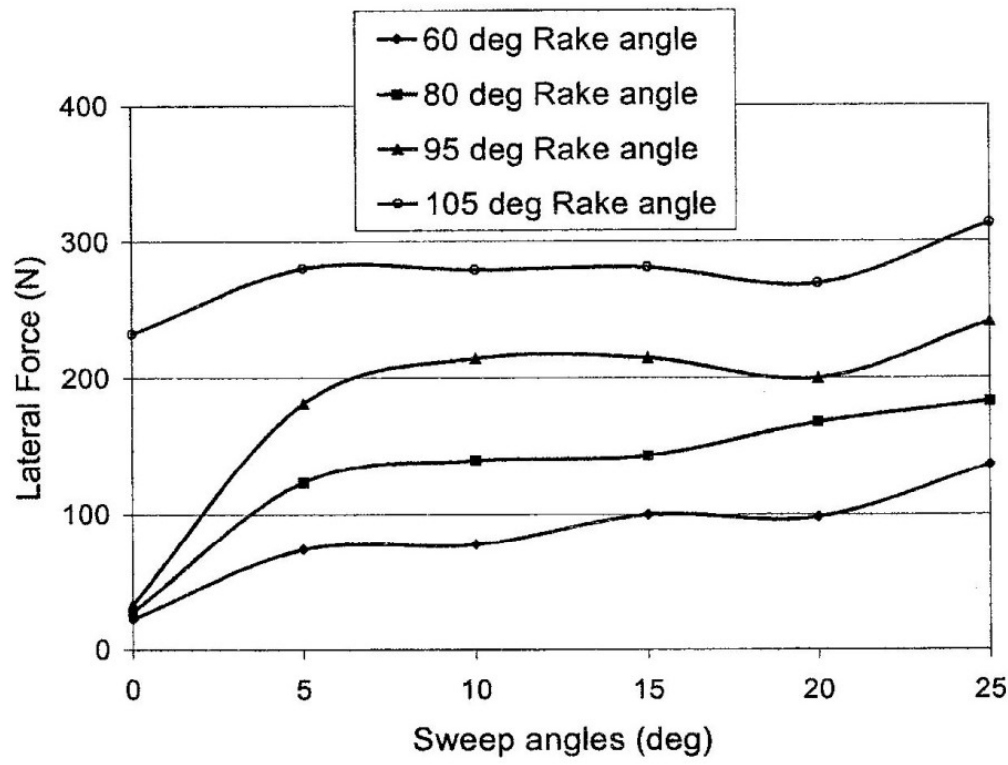

Figure 9. Effect of sweep angle on lateral force acting on non-rotating disc

The difference in variation of lateral force at small and large sweep angles can be explained by the fact that at smaller sweep angles a smaller volume of soil was failed ahead of the disc as compared to the volume of soil failed by larger disc sweep angle. Thus if a resultant passive force is considered, lower resultant force will be encountered at small sweep angle and increased as the disc sweep angles are increased. However for both discs the trend of the variation of the lateral force showed to increase with the increase of rake angles.

The comparison of the variations of lateral force acting on both discs (Figure 10) showed that the lateral forces generated by a rotating 
disc were higher than that encountered by a non-rotating disc. This is because the resultant passive force on a rotating disc acts perpendicular to the interface of the disc and on a non-rotating disc the resultant passive force act at a certain angle equal to the angle of soilmetal friction. Therefore the lateral force component for a rotating disc is larger than that of a non-rotating disc.

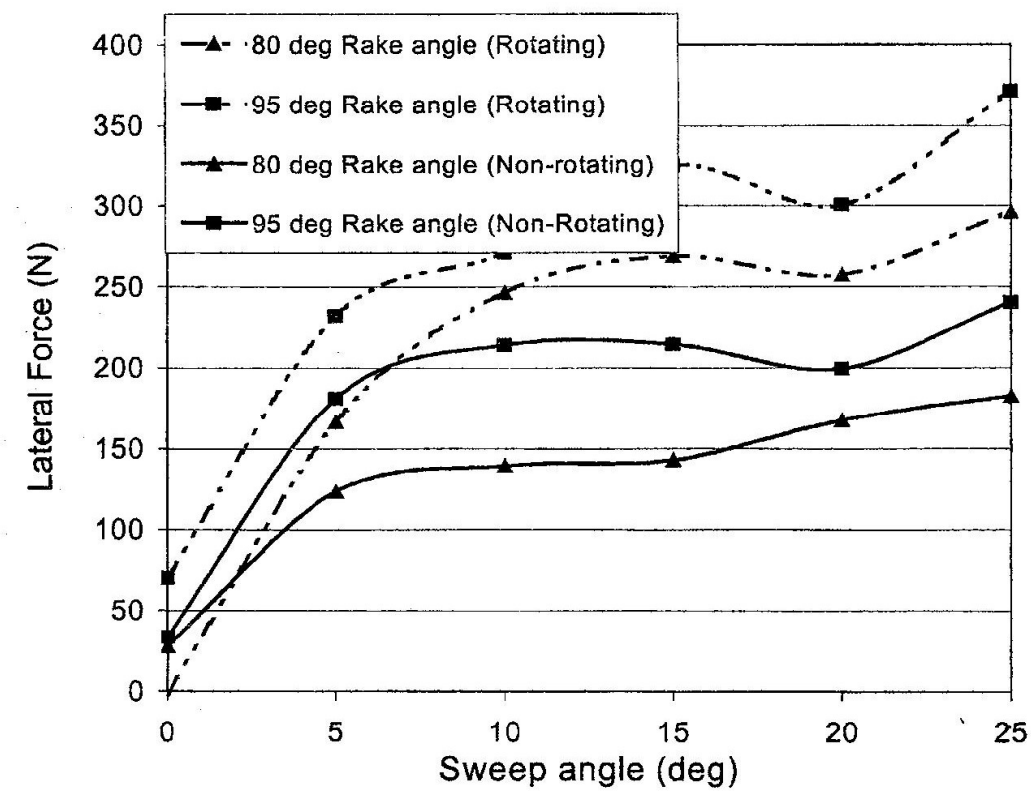

Figure 10. Comparison of the effect of sweep angle on lateral force

In order to have better performance of the plain disc during ploughing, it is important to have minimum draught and maximum lateral forces. For that matter rotating disc could better be coupled on the disc plough than non-rotating disc because it had these two advantages over the other.

The results of the forces generated by the rotating disc showed that minimum draught forces occur in the range between $8^{\circ}$ and $12^{\circ}$ sweep angle. A minimum upwards vertical force appeared in the range between $5^{\circ}$ and $12^{\circ}$ disc sweep angle and a maximum lateral force was found to be in the range between $5^{\circ}$ and above. These results suggested that, there was no single angle, which gave minimum draught force, minimum upward vertical force and a maximum lateral force. But since the penetration and stability of the plough are of greater importance, the optimum sweep angle would therefore lie in the range between $8^{\circ}$ and $12^{\circ}$. In this range the upward vertical force is minimum and the lateral force is maximum but at a cost of $33 \%$ increase in draught force over the minimum value.

The results obtained from the investigation of rake angles for a rotating plain disc showed that the minimum draught force occur in the range between $60^{\circ}$ and $80^{\circ}$. The minimum upward vertical force is obtained in the range between $60^{\circ}$ and $80^{\circ}$, and a maximum lateral force occurs in the range from $85^{\circ}$ to $105^{\circ}$. These combinations of results made it difficult to select the optimum range, however the compromising range seems to be between $80^{\circ}$ and $95^{\circ}$ disc rake angle. The penalty for this range will be the increase in upward vertical force, which could be counteracted by the effect of sweep angle setting. 
Although the experiments were conducted in one type of soil, it is expected that the trends in force variations with angles would remain the same for other soil types (Gordon, 1941). It is only the magnitude of the forces that could change. In that case the recommended sweep and rake angles will hold even for other types of soils.

\section{CONCLUSIONS}

The general trends of the forces obtained from the experimental work correlates well with the previous work done by other researchers using other types of tools (Gill et al, 1980; Godwin et $a l, 1987)$. The variations in vertical force with rake angle were similar to the work done by Clyde (1939) and Payne and Tanner (1959) because in all cases there was a decrease in the upward vertical force as the rake angles were decreased.

The rotating plain disc is recommended to counteract the problem of high side forces generated by disc ploughs rather than a nonrotating plain disc because of lower draught forces and larger lateral forces encountered when using this type of disc. The recommended optimum angles lie between $8^{\circ}-12^{\circ}$ for disc sweep angle and $80^{\circ}-95^{\circ}$ for disc rake angle. Further study is recommended to investigate the effect of cornering to the disc forces, as it is not possible for the machine operator when ploughing to move only in a straight line as it was during the experimental work. It is also recommended that, the effect of high side force can be avoided if other types of disc implements will be designed basing on the principle of generating equal and opposite side forces.

\section{REFERENCES}

1. Clyde A.W. Improvement of Disc Tools, Agricultural Engineering, 20: 215-221, 1939.
2. Dally, J.W and Riley, W.F. Instrumentation for Engineering Measurements, John Wiley, New York, 1983.

3. Gebresenbet, G., Measurement and Prediction of Forces on Mouldboard Plough Bodies, Proceedings of the Eleventh International Congress on Agricultural Engineering, Dublin, September $4-8$, pp.1539-1546, 1989.

4. Gill R.W, Reaves W.C, and Bailey C.A. The Effect of Geometric Parameter on Disc Forces, Transactions of the American Society of Agricultural Engineering 23, 266-269, 1980.

5. Godwin R.J, Seig D.A, Allot M. Soil Failure and Force Prediction for Soil Engaging Discs. Journal of soil use and management, volume 3, No. 3, 1987.

6. Godwin R.J, Spoor G and Kilgour J. The Design and Operation of a Simple Low Cost Soil Bin, Agricultural Engineering Research Journal, 25, pp. 99-104, 1980.

7. Gordon E.D. Physical Reactions of Soil on Plough Discs, Agricultural Engineering 22, 205-208, 1941.

8. Hettiarachi D.R, Reece A.R, The Calculation of Passive Soil Resistance. Journal of Geo-technique 24 (3), 289-310, 1974.

9. Macartney J.C, Northwood P.J, Dagg M, and Dawson R. The Effect of Different Cultivation Techniques on Soil Moisture Conservation on The Establishment and Yield of Maize at Kongwa, Central Tanzania, Tropical Agriculture (Trinidad) 48: 9-23, 1971.

10. Payne P.C.J and Tanner D.M. The Relationship Between Rake Angle and the Performance of Simple Cultivation Implements, Journal Agricultural Engineering Research. 4; 312-325, 1959.

11. Sheruddin B, BalochJ.M, Ghulam R, Zafarullah, and Panhawar S., Effect of Disk and Tilt Angle on Field Capacity and Power Requirements of Mounted Plough, Agricultural Mechanization in Asia, Africa, and Latin America Vol. 23, No. 2, pp. 9 13, Spring 1992. 